\title{
GPR for mapping fractures for the extraction of facing granite from a quarry: A case study from Republic of Karelia
}

\author{
E.P. Isakova, S.M. Daniliev, T.A. Mingaleva \\ Saint-Petersburg Mining University, Department Of Geophysical And Geochemical Methods Of \\ Prospecting And Exploration Of Mineral Deposits, 2, 21st Line, St Petersburg 199106, Russia
}

\begin{abstract}
The main idea of the article is the problem of choosing the optimal complex of geophysical methods to study the coverage and localization of cavity in the rock massif. The necessity of using ground penetration radar (GPR) work on the facing stone deposits in the process of massif research has been identified and justified. Based on the study, the author proposed the use of two types of antennas with the aim of penetrating to different depths. The presented conclusions prove that using georadar for study of fracturing in a facing stone deposit could be effective.
\end{abstract}

\section{Introduction}

The extraction of facing stone today is a continuously evolving industry of the mining complex. Unfortunately, when exploring deposits of facing stone, there is a high probability that geological forecasts will not correspond to the real outputs of the blocks. In accordance with this, it is necessary to supply geophysical methods into the geological exploration that increase the quality of the result obtained. The fact that the main and primary efforts in the exploration of facing stone deposits are aimed at studying the fracturing of the rock mass is a main parameter for the quality of raw materials.

To assess the quality of granites, later used as block raw materials, it is necessary to evidence the nature of the fracturing of the granite massif. The presence of fracture determines the size and yield of blocks. Cavity of various directions are found in granite massifs: vertical, horizontal, inclined, etc. In this case, the cavity cross to each other and form parallelepiped, which further characterizes the output of the block stone. The presence of exactly horizontal cavity in the massif is a marker of the horizon, that helps during the extraction on the open-cut.

Each facing stone deposit is unique. There is a need for detailed exploration of deposits to determine fractures of various directions, lengths, etc.

The feature of the facing stone deposits involves the use of shallow geophysical methods with high resolution. In particular, there is experience in conducting georadar work on the facing stone deposits, which is an effective method in studying this problem. This method has proven itself in the study of the upper part of the geological environment, is sensitive to 
low-power heterogeneities, solves a wide range of problems, has high productivity and relatively low cost [1].

When studying the possibility of using geophysical methods in the development of block stone deposits on the example of work carried out by the KarRC RAS [9] an approach was identified and tested for studying block stone in the North-West of Russia and the Urals using magnetic prospecting and electro tomography, as well as experimental georadar works. This complex increases the profitability and stability of the enterprise at all stages of work. With regard to other geophysical methods, in particular the GPR method, they are advisory in nature, depending on the lithological composition of the rocks that make up the field. The methods complement each other, which allows you to obtain more detailed information about the object under study. It is noted that the use of GPR studies can either be applied or not, depending on the thickness and composition of Quaternary deposits of 1.5-2 m, different-altitude relief of primary work, clay deposits, as well as the lithology of the field. It is also necessary to correlate the georadarogram data with verification wells (it is proposed to drill 8-10 wells at the site). Next, conduct a study of the core with a step of 1 $\mathrm{cm}$ to identify the intervals of fracturing and the angle of incidence, as well as to determine the monolithic rocks of the study area $[1,11]$.

World experience shows similar studies for the optimization of geophysical technologies and the choice of a rational complex $[1,7]$. The stone distribution market is currently in progress.

Finland, a country with a huge potential, is almost entirely located in the area of the crystal shield, and makes its own demands for facing stone. Just like in Italy, blocks have been mined since ancient times. At the same time, Finland is the largest exporter of granite blocks (about 70 thousand $\mathrm{m}^{3}$ annually). The most popular are the Ristijärvi granites (light gray fine-grained granites). As a global supplier of block raw materials,Finland is interested in increasing profits by finding optimal sites for the development and operation of block raw materials.

In this regard, the Finnish industry makes special demands in the search and exploration of deposits of facing stone. At the moment, a complex of geophysical methods is used in the exploration of areas, aimed at localizing fracture zones. A lot of works have been devoted, within the framework of which the substantiation and proof of the effectiveness of the applicability of geophysical research is carried out. In particular, the GPR method has shown its high efficiency and is recognized as the leading one in the geophysical complex for studying granites $[1,6,7]$.

\section{Acquisition and data processing}

The main goal in the operation of a block stone open-cut is to extract large blocks that have standard sizes and without troubles. In planning and for reserve calculation, it is necessary to know the structural characteristics of the massif. The structure and orientation of fracture zones in the field is fundamental to optimize investment and enterprise development. The identification of a block stone deposit near transport routes is of rather high commercial value and considerable interest for mining companies $[8,10]$.

The production of facing granite is carried out in the form of blocks with a parallelepiped shape with the required size. Extracted blocks of stone are transported to another locality where further polishing takes place. To assess the prospects of a block stone deposit, knowledge of the fracturing systems and any other disturbances common in a given quarry is necessary. It is also necessary to take into account the spatial arrangement 
of subhorizontal cavity that regulate the volume of blocks. Assessment of the localization of cracks in space and weathering zones can be done using ground-based GPR survey.

GPR is an electromagnetic method that uses high-frequency $(10 \mathrm{MHz}-2.5 \mathrm{GHz})$ radio waves to create high-resolution images to determine a variety of geological features, such as splits, cavities, faulting, and weathered layer [9].

The use of GPR to localize cavities in granite rocks on the territory of the Republic of Karelia is advisory in geological exploration at the facing stone deposit. For these purposes, GPR studies were conducted at one of the deposits to identify the effectiveness of using the proposed method.

The main objectives of the GPR study were to determine the location of the fracture and weathered layer, as well as the indication of rocks base.

During geological studies of the area, it was noted that granite bodies contain structures such as fracture zones (both inclined and subhorizontal), blocks of different sizes, isolated by cavities, filled mainly with water due to the passing aquifer near the deposit and climatic conditions. In this regard, it was assumed that the fracturing would be easily detected using GPR, as there is a large contrast in the relative permittivity between the granite massif and the cavities filled with water [2].

\section{Interpretation and discussion of results}

This paper presents studies of a site at one of the facing stone deposits in the Republic of Karelia. Crystalline rocks of the Fennoscandian Shield are widespread in the Republic of Karelia, suitable for use as facing stones. These breeds have a number of pronounced physical features (increased resistance, speed of propagation of elastic waves, etc.), which increase the contrast of the data obtained for subsequent study in geophysical fields.

The study area is composed of Archean and Proterozoic formations, protruding to the day surface or covered by Quaternary formations. Archean rocks are almost ubiquitous and are represented by granites of the first and second groups. Proterozoic formations have a less widespread environment, but are very significant, since ore minerals are associated with them.

Field work was performed using the OKO-2 GPR company with two frequency ranges $150 \mathrm{MHz}$ and $1200 \mathrm{MHz}$. In this work, a frequency of $150 \mathrm{MHz}$ was used to map deep cavities, while $1200 \mathrm{MHz}$ was used for higher resolution studies of the surface of the array. 


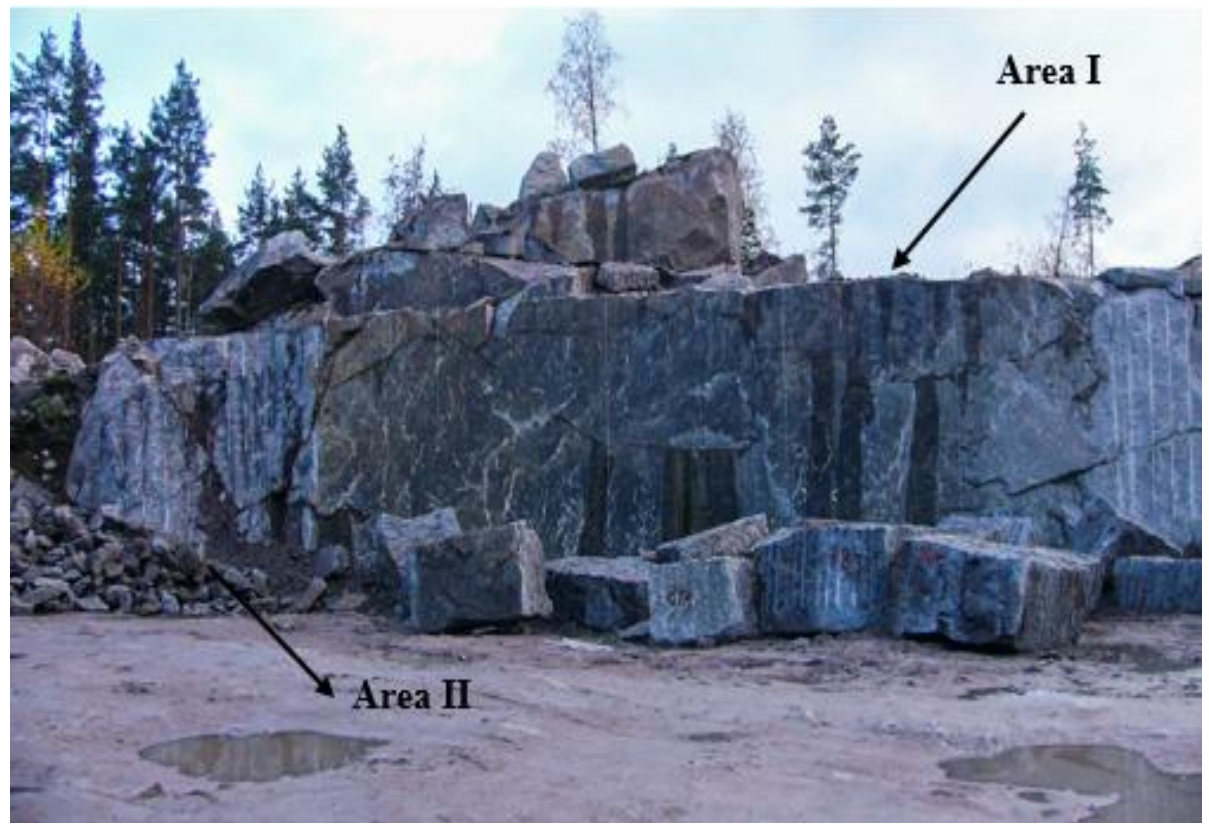

Fig. 1. GPR section of the studied rock mass.

The study of the granitoids massif was carried out on the example of a site located in the Republic of Karelia. An experimental georadar sounding was carried out on a partially discovered part of the field. Due to the uneven thickness of the Quaternary sediments $(0.3$ 3 meters) and near-surface heterogeneity of bedrock (fracture, the presence of xenoliths of the main rocks), the maximum sounding depth was not more than 5 meters. However, it made sense to put georadar sounding along two or three profiles after working out the first horizon, for the need to track subhorizontal fracturing. According to the documentation, during the development of the field, subhorizontal fracture zones developed in the granitoid massif were recorded [6].

The main structural feature of the rock massif is the presence of numerous weakening surfaces or various inhomogeneities from contacts between individual mineral grains, micro and macro fractures to regional and planetary discontinuous structures - faults $(2)$. The degree of distribution of heterogeneities is not the same, however, rock masses are highly characterized by a high ordering of their spatial orientation.

GPR profiles are located in two separate parts of the quarries (Fig.1): the highest topographic

part (area I) and the career front after overburden and mining of the first horizon (area II).

The site is an open-cut partially opened for development. On the day surface there is a large amount of block raw materials, which impedes research. After opening the first horizon, a system of large cracks was observed, which were clearly visible. Also, these cavities are water-filled, because At the time of the work, atmospheric precipitation was observed, and according to hydro geological studies, there is an aquifer near the quarry, which also spreads through a system of cracks.

GPR studies were carried out in two areas of the quarry to identify both the weathering zone and the fracture zone, which was observed visually after the penetration of the first 
horizon. This case is convenient for research, because You can correlate the data and identify search attributes.

GPR data were processed using PRISM 2.5 software (www.radsys.lv). Various filters and options are used to suppress noise and noise that interfere with the correct interpretation. The cosine band pass filter (Ormsby band pass) is used to improve the signal-to-noise ratio. Fk filtering was used to remove lateral reflections from the walls of the open-cut. Fk migration was also used to spatially measure the position of reflectors in a granite massif. To ensure some horizontal smoothing, a spatial moving average filter is used. Hilbert transform (energy) is used to isolate the energy of a reflector in granite $[1,5]$.

GPR sections show a detailed display of inclined and subhorizontal reflectors for approximately $15 \mathrm{~m}$ depth, as well as hyperbolic shallow reflectors. Pronounced refractions are always associated with high energy reflections of the EM signal. All reflectors are interpreted on the basis of available geological information and correlate with known fracture planes distributed in the granite massif.

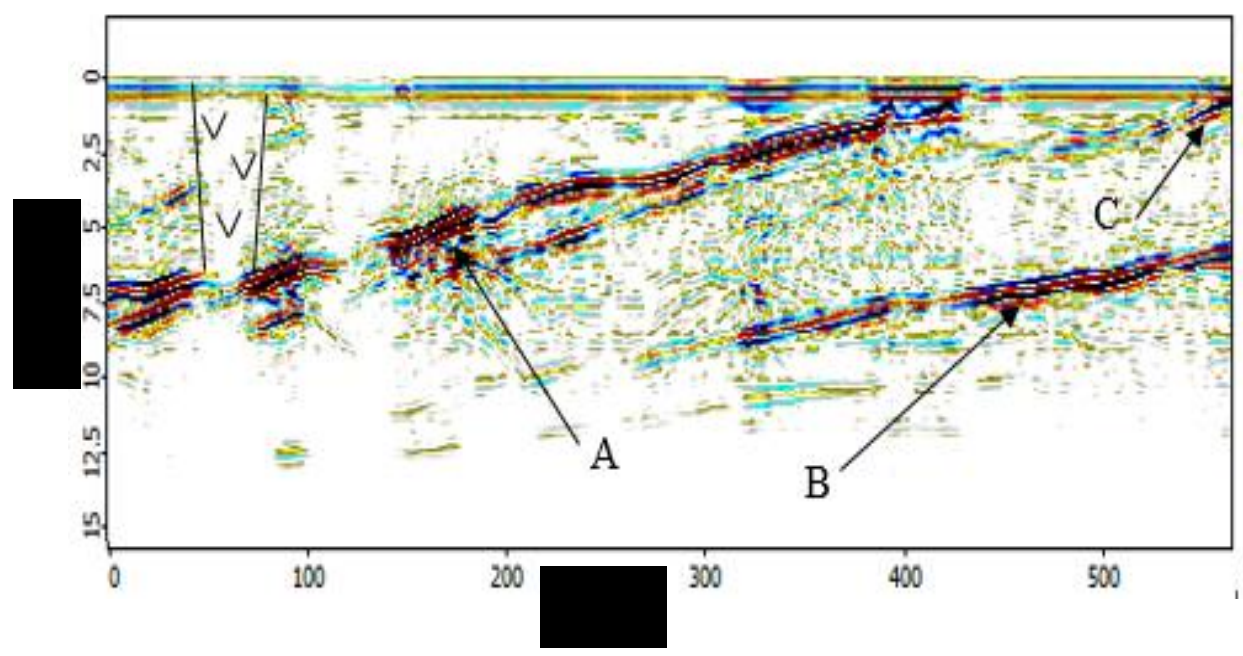

Fig. 2. GPR profile obtained in area I by an antenna of $150 \mathrm{MHz}, \mathrm{A}, \mathrm{B}, \mathrm{C}$ - reflectors associated with subhorizontal cavity, probably filled with water.

Profiles did not need correction with relief, because measurements were taken along a cleared site of a horizontal level.

In fig. 2 shows a $150 \mathrm{MHz}$ profile with a length of $56.4 \mathrm{~m}$ obtained in region I near the location of visible cavities. Contrast bands highlighted in Figure A, B and C indicate a sharp change in energy. The profile was selected on a cleared from boulders and block stone remains, it is not subject to overburden operations at the quarry, therefore, the weathering zone in this case was preserved. The weathering layer is traced in the thickness along the GPR section at a depth of $1 \pm 0.5 \mathrm{~m}$. Irregular reflectors are observed here, which corresponds to granite altered by weathering. According to observations and geological records, filling of the vertical disturbance of the granite massif with clay material was noted. It is worth noting that this subvertical cavity does not have a pronounced manifestation in the GPR section, while the attenuation of electromagnetic waves characteristic of clay material is observed. There are two strong reflectors - (A) a depth of about 5-7 m, going downhill, and a reflector (B) with a depth of about 8-10 m, both of which are in the high-energy field. These reflectors are associated with subhorizontal 
hollowly falling cavities, which are probably filled with water due to their proximity to the aquifer, as well as precipitation. The large amplitude of the reflectors is caused due to the large contrast in the dielectric constant between water and the granite massif.

A hollowly inclined lying reflector (C) with an approximate depth of $5 \mathrm{~m}$ and associated with high energy also indicates a water-filled cavity.

Between the two fracture systems (A) and (B), with a thickness of about $5 \mathrm{~m}$, one can see an area with almost no reflections, which most likely indicates monoliths. Below cavity (B), there is a lack of reflections and, consequently, low energy return, which also implies the existence of a homogeneous monolithic granite rock - a good quality rock for production.

Observed wet cavity, both inclined and subhorizontal, along the visible part of the pit wall, which are comparable to cracks mapped by the georadar, can serve as proof of the applicability of the GPR in a facing stone deposit. In connection with this evidence, one can judge the correctness of the data obtained by georadar.

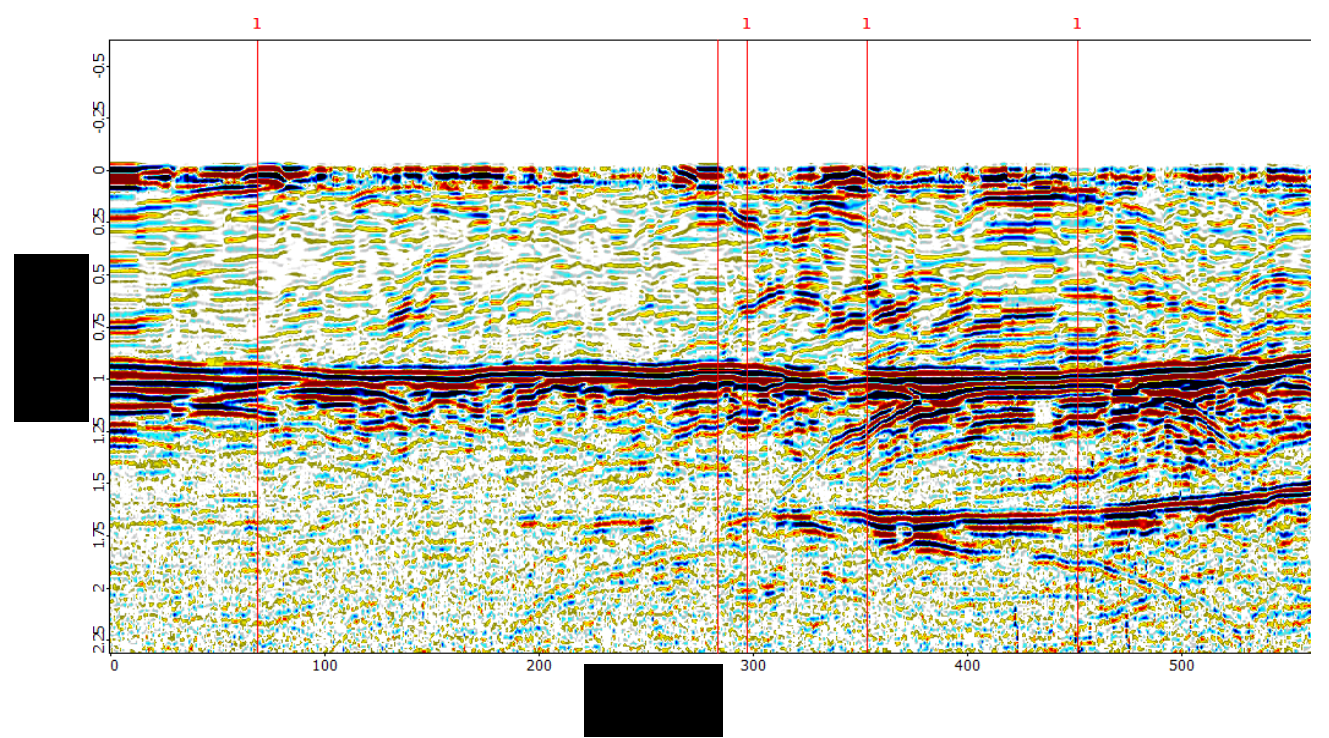

Fig. 3. GPR profile obtained in area I by a $1200 \mathrm{MHz}$ antenna.

In region I, using a $1200 \mathrm{MHz}$ antenna, a GPR section of the upper part of the studied array was obtained. As can be seen from Figure 3, the research depth was approximately $2.5 \mathrm{~m}$, this depth is enough to determine the weathering zone to estimate the thickness of the weathered rock. Therefore, it makes sense to conduct georadar studies using two antennas. As can be seen from Figure 3, the first meter of the section is quite noisy, which may indicate the presence of a weathering zone. Below $1.5 \mathrm{~m}$, a relatively quiet distribution of EM waves is observed, which may correspond to monolithic zones.

After opening the first horizon of the granite massif, a georadar study was also performed to assess the prospects of working out the lower horizons. At this stage, measurements were made using a georadar with an antenna of $150 \mathrm{MHz}$, because there is no need to determine the weathering zone after sinking.

In field II, a georadar study was conducted. The profile length was $60 \mathrm{~m}$; the frequency of the emitted signal was $150 \mathrm{MHz}$. On the upper parts of the profile, zones with high reflection can be seen, which is most likely due to the fact that at the moment of separation 
of the block or when opening the horizon from mining equipment a load on the rock occurred, which was expressed in a system of microcracks with a thickness not exceeding 1 $\mathrm{m}$.

In addition, there are two zones (A) and (B), which extend to a depth of approximately $10 \mathrm{~m}$. These areas may be associated with the presence of fracture zones, which scatter and reflect energy. Moreover, these systems are parallel to each other, but the presence of other reflectors between them can indicate poor-quality granite raw materials. Reflections are probably related to the uneven surfaces of the disruption planes that have local cavities. Therefore, this granite zone is less advantageous for extraction due to probable cavities [2].



Fig. 4. GPR profile obtained in region II by a $1200 \mathrm{MHz}$ antenna.

Another reflector $(\mathrm{C})$ is also associated with an inclined fracture that extends across other cracks.

Along the entire profile, one can observe a zone with a noticeable absence of reflectors below about $10 \mathrm{~m}$. This part is interpreted as the top of a monolithic, not fractured granite rock, which can be used for commercial mining.

\section{3D-Modeling}

Modern software allows us to solve a wide range of problems for optimizing the processes of exploration and exploitation of mineral deposits, which has a positive effect on geological-mining surveys. The rapid progress in the processing of huge amounts of geological information has determined the development trends of modeling and visualization to determine the real situation at various stages of exploration $[3,4]$.

Having most clearly demonstrated the object of study, it will allow to obtain primary knowledge about the object in the form of various sets of properties and parameters, which in the future will contribute to the maximum efficiency of production activities. Currently, the use of volumetric modeling is implemented at all stages of the exploration process. Using modeling,it is possible to make a further forecast for the development of some properties of the object under study. Therefore, it is necessary to introduce computer simulation and optimization methods used in the development of deposits for various types of minerals.

Volumetric modeling was carried out over a series of 7 profiles of $30 \mathrm{~m}$ using the OKO2 GPR with an antenna of $150 \mathrm{MHz}$. The research depth was about $16 \mathrm{~m}$. The studies were conducted on the day surface. For the subsequent correlation, a section with an open pit 
wall was selected. The cracks are mapped not only on the walls, but also on the surface itself, which allowed us to link geophysical observations with geological data.

a)

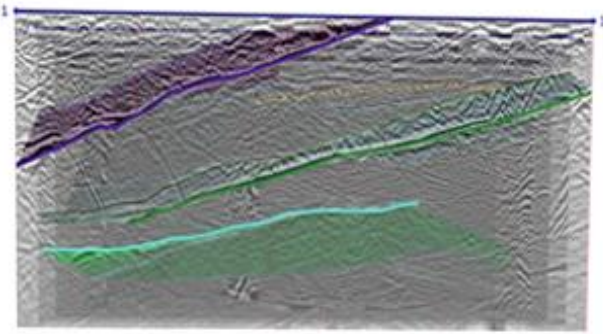

b)
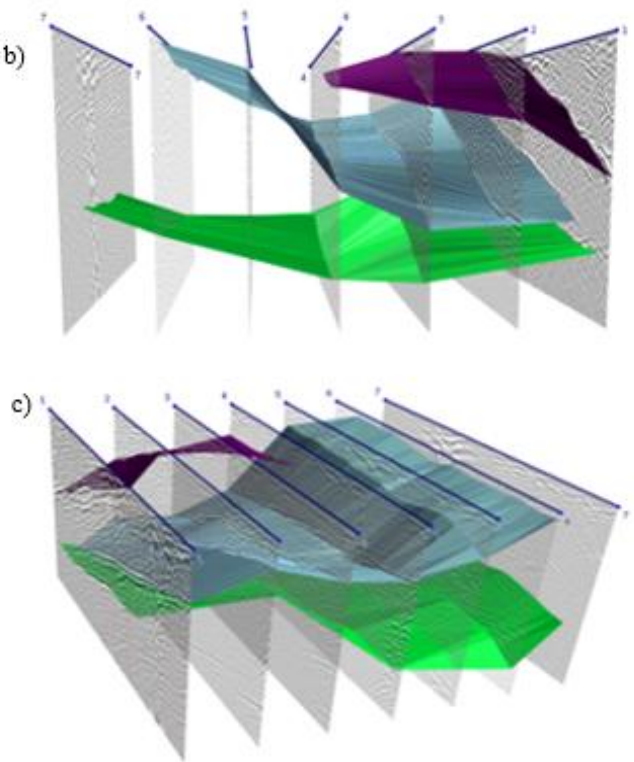

Fig. 5. 3D model of cavity propagation in the studied area, performed in various directions: a northern, $\mathrm{b}$ - western, $\mathrm{c}$ - northeast.

Thus, based on GPR, a volumetric model of the distribution of cavities in a granite massif is constructed. Based on three waterlogged cavities visible in the open part of the quarry, because the different dielectric constant of such cavities in the granite massif is a contrast reflector. Figure 5 shows that the cracks in the massif do not lie in the plane in parallel or even non-tilted, but represent a chaotic direction, possibly due to the presence of inclusions in the granite or other cavities that prevent the rectilinear propagation.

The volumetric modeling conducted in this work requires further refinement and implementation in the interpretation of georadar studies.

\section{Conclusions}

Georadar studies performed on the Kashina Gora field site in the Republic of Karelia using OKO-2 tool with $150 \mathrm{MHz}$ and $1200 \mathrm{MHz}$ antennas made it possible to detect fracture 
systems (both inclined and subhorizontal), the weathered layers, and also determined the location of the blocks isolated at a depth between the weatheredlayers and the cavities. As a result, zones with a practical absence of reflectors (and, accordingly, with low energy) associated with the transmission of a georadar signal through a monolithic granite massif were identified. There is ground penetration in various parts of the quarry to optimize the mining process. So, it was revealed that when passing the first horizon, a system of cavities spreads deeper, and the granite lying between them has low-quality characteristics, therefore, the development of the second horizon will not bring economic benefits to the enterprise.

The best results were obtained using an antenna of $150 \mathrm{MHz}$, which is able to give a detailed image to a depth of $25 \mathrm{~m}$.Using the antenna

$1200 \mathrm{MHz}$ is also appropriate for identifying and mapping the weathered layer, which plays a huge role in opencast development.

The sub horizontal and inclined cracks located in the granite massif are excellent planes for the extraction and removal of large blocks. Successful mapping of these zones is very important for the extraction process, because it is these fracture zones that bring economic benefits by reducing the use of explosives, which greatly facilitates the extraction of commercial blocks during production.

The results show that the GPR method does not detect vertical cavities. However, troublesome zones filled with clay material show a GPR signal with a characteristic absence of reflections, thus allowing them to be identified. On the other hand, the absence of reflection usually indicates a monolithic rock. The distinction between vertical fracture zones and monolithic rock can be obtained by joint interpretation with geological information.

Mapping the positional relation of inclined and subhorizontal cavities, weathered layers and zones without reflectors is important for determining the most advantageous locations for the extraction of granite blocks of better quality. These results are fundamental for the interpreter, and are the basis for exploration and exploitation of the quarry, and, thus, allows you to orient the front of production in order to minimize operating costs for the enterprise.

\section{References}

1. Isakova, E.P., Daniliev, S.M., Danilieva, N.A., Ashker, G.Kh. Bulletin of the Tomsk Polytechnic university. Engineering of georesourcesStudy of fracturing at the facing deposit stone with the use of the method of GPR 140-145 (2020).

2. Arosio, D. Journal of Applied GeophysicsRock fracture characterization with GPR by means of deterministic deconvolution, 27-34 (2016).

3. Lalomov, D.A, Glazunov, V.V. GeoresursyEstablishing the relationship between mineralization and quality factor based on georadar data 1, 69 - 77 (2017).

4. Dashko,R. E., Karpova, Y. A. SGEMEngineering geology and geotechnics of fractured clays as building base and surrounding medium (by the example as clayey bedrocks in Saint-Petersburg)3, 85 - 92 (2016).

5. Dashko, R. E,Kotiukov, P. V. Fractured clay rocks as a surrounding medium of underground structures: The features of geotechnical and hydrogeological assessment1, 241 - 248 (2018). 
6. Henninen, P. Fourth International Conference on Ground Penetrationg Radar, Geological Survey of Finland, Special Paper Recent improvements in ground penetrating radar365 (1992).

7. Porsani, J.L. A case study from southern Brazil Journal of Applied Geophysics GPR for mapping fractures and as a guide for the extraction of ornamental granite from a quarry $177-187$.

8. Ryazantsev P.A. Increasing the efficiency of exploration of facing stone deposits based on electrotomography169 (2015).

9. Sokolov, S. Ya, Klimovsky, A.V.\&Kuzminykh, E.N. Theory and practice of mining, processing and the use of natural stoneState of the art on the application of geological and geophysical methods in the search, assessment and exploration of a block stone 35-58 (2016).

10. Tutakova, A.Ya.,Romanovsky, A.Z.,Bulakh, A.G. St. Petersburg: Russian Collection Facing stone of the Leningrad region. Granites of the Karelian Isthmus in the modern architecture of St. Petersburg, 80 (2011).

11. Ushakov, I.N. ZapiskigornogoinstitutaFracture of the mountain mass in the central region of Donbass and the point method of its characteristics 36 (2018). 